\title{
BLAST EFFECTS AND DAMAGE CHARACTERIZATION ON REINFORCED MASONRY WALLS AT FULL-SCALE
}

\author{
MARÍA CHIQUITO ${ }^{1}$, LINA M. LÓPEZ1 ${ }^{1}$ RICARDO CASTEDO ${ }^{1}$, \\ ANASTASIO P. SANTOS ${ }^{1} \&$ ALEJANDRO PÉREZ-CALDENTEY ${ }^{2,3}$ \\ ${ }^{1}$ Universidad Politécnica de Madrid, ETSI Minas y Energía, Spain \\ ${ }^{2}$ Universidad Politécnica de Madrid, ETSI Caminos, Canales y Puertos, Spain \\ ${ }^{3}$ FHECOR Consulting Engineers, Spain
}

\begin{abstract}
It is of a great importance to find out materials that improve the response of different structural elements against a blast event. While there are many works about reinforcing structures, there are a reduce number of them that presents blast test at full-scale. The aim of this work is the comparison of different constructive solutions that are candidates to improve the integrity of brick masonry walls against moderate explosions. This kind of constructive elements produce in many cases, when structure does not collapse, more casualties due to spalling phenomena. A total number of 16 walls were performed at full-scale (measuring $2.5 \mathrm{~m}$ length, $2.5 \mathrm{~m}$ width and $240 \mathrm{~mm}$ of thickness) for this purpose. Charge for the tests ranged from 18 to $38 \mathrm{~kg}$ TNT Equivalent and was located at $5 \mathrm{~m}$ from the target. The scaled distance was selected so the damage on the wall was intermediate (in the halfway between collapse and little cracks) in order to detect differences among the solutions tested. Three alternatives of reinforcement have been developed: a fibered mortar, a recycled carbon fibre mesh impregnated with a semi-fluid epoxy adhesive and a polymer primed glass fibre mesh applied with a water and polyurethane-based adhesive. The blast event has been characterized using pressure gauges, accelerometers, high-speed camera and a laser-scanner. The resulting damage has been evaluated on both wall faces trough 20 defined points using a rebound hammer. Damage maps has been drawn for each wall doing an interpolation on 200 points. The damage has also been evaluated on terms of spalling, which is the mass of fragments launched during the test. According with the results, reinforcement influences the response significantly.
\end{abstract}

Keywords: brick masonry wall, damage, blast, full-scale testing.

\section{INTRODUCTION}

Although the terrorist threat is not a new problem, in recent years, the way to carry out terrorist attacks as well as the locations where they happen are changing. Nowadays, any civilian building such as schools, theatres, and hospitals could become a target. Due to that, a double challenge appears for the Scientific Community. As important as assuring the structural integrity is to improve the strength of masonry walls since, when structure does not collapse, is the main source of casualties and injuries due to fragment launched [1]. Moreover, the search of solutions capable to improve the response of masonry walls should be able to be applied on existing buildings [2].

While there are many works about reinforcing structures, there are a reduce number of them that presents blast test at full-scale [3] on brick masonry walls. Working at full scale is of a great importance for the reliability of the results.

The aim of this work is the comparison of different constructive solutions that are candidates to improve the integrity of brick masonry walls against moderate explosions. These solutions can be applied in a simple way, both in new or existing buildings. 


\section{TEST DESCRIPTION}

Four tests at full scale with three different solutions were tested. For each test also, a control wall without reinforcement was developed in order to compare results and assess the differences between the solutions.

The charge was located equidistant at five meters from each of the four walls.

Test one (T1) and test three (T3) had the same setup with the protective solution laid out in the outer face, that means, the face exposed to the explosive charge. On the other hand, test two (T2) and test four (T4) had the protective solution in the inner face, the opposite side to the explosive charge.

All the walls were fastened only by the top with a steel support by welding points and to the ground for each own weight, simulating the normal fastening of a wall. Fig. 1 shows the tests arrangement.

\subsection{Scaled distance and explosive charge}

The most common practice of explosion scaling is based on 'cube root' scaling. It states that equivalent pressure occurs at scaled distance $\mathrm{z}$ :

$$
z=\frac{R}{W^{1 / 3}},
$$

where $\mathrm{R}$ is the distance from the explosion (standoff distance) and $\mathrm{W}$ is the charge weight. According to published works on brick masonry walls [4]-[6], unreinforced wall would collapse when the scaled distance was less than $1.82 \mathrm{~m} / \mathrm{kg}^{1 / 3}$. The scaled distance initially selected for the first test $\mathrm{T} 1$ was $1.84 \mathrm{~m} / \mathrm{kg}^{1 / 3}$, because the objective was to obtain medium damage in order to observe differences in the solutions response.

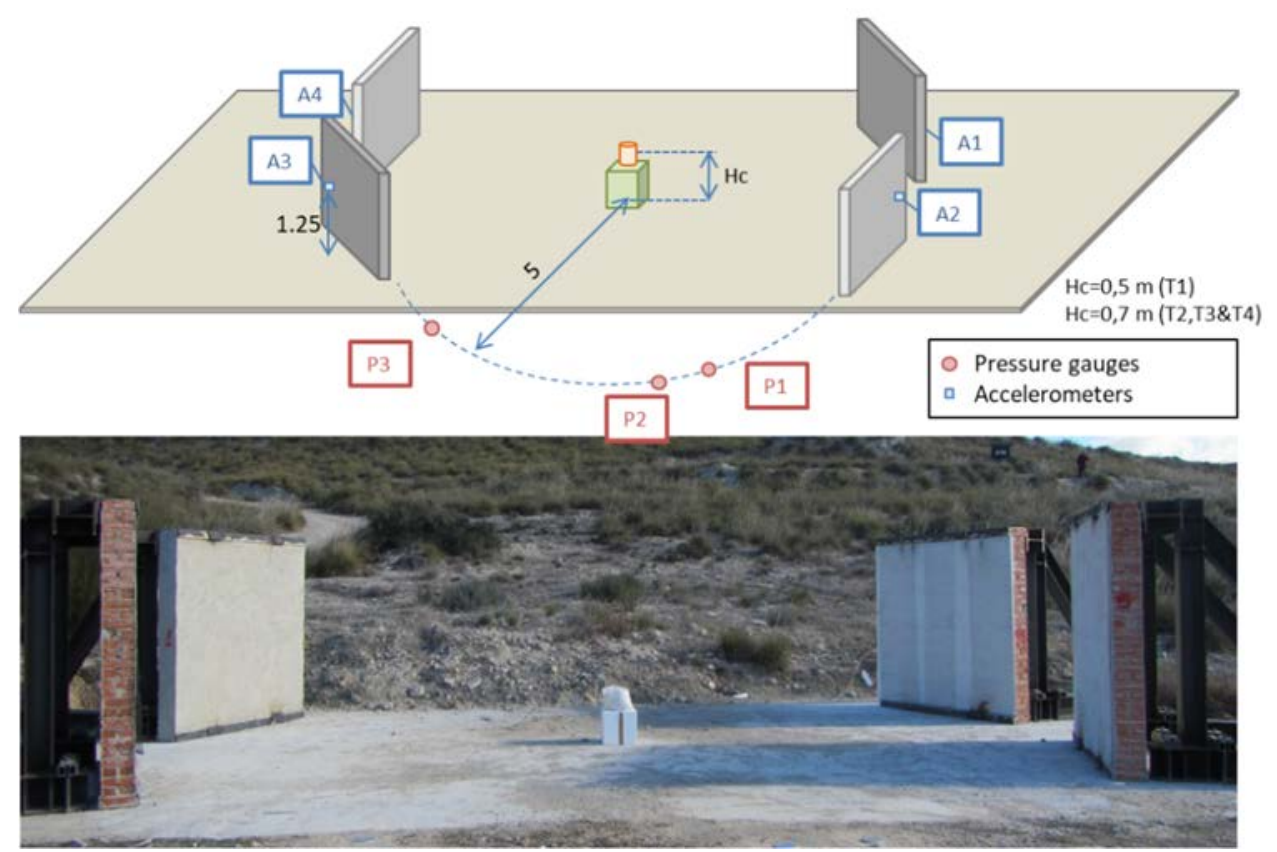

Figure 1: Test set-up. 
This value was progressively reduced (1.71 for test $\mathrm{T} 2$ and $\mathrm{T} 3$, and 1.49 for $\mathrm{T} 4$ ) to increase the damage on the walls.

The explosive was a Dynamite type - a civil explosive with experimental TNT equivalent based on pressure of 0.79 . Charge shape was bag-shape close to cylindrical and was initiated in the centre with a conventional detonator. Explosive mass was located on a porexpan cubic support so the height of the charge (distance from the centre of the charge to the floor) was $50 \mathrm{~cm}$ for $\mathrm{T} 1$ and $70 \mathrm{~cm}$ for $\mathrm{T} 2, \mathrm{~T} 3$ and $\mathrm{T} 4$. Table 1 summarizes the charge characteristics.

\subsection{Constructive data}

Sixteen walls were performed at full scale, measuring $2.5 \mathrm{~m}$ length, $2.5 \mathrm{~m}$ width and $240 \mathrm{~mm}$ of thickness for the tests. They were built with calcium bricks and joined with standard mortar. Furthermore, three different solutions developed by MAPEI $^{\circledR}$ were tested. Each solution was laid in four different walls.

Solution A: Two-component, fibre-reinforced, bi-component premixed mortar with high ductility based on hydraulic lime natural (NHL) and Eco-Pozzolanic, light coloured, particularly suitable for reinforcement structural support of masonry supports and for the regularization of stone, brick and tuff surfaces.

Solution B: High-strength carbon fibre mesh for "reinforced" structural strengthening of masonry and concrete structures with a thixotropic epoxy adhesive for impregnating fabrics using the "dry system".

Solution C: Bi-directional, primed, glass fibre reinforcing fabric for localized reinforcement applications on all types of non-load bearing and non-structural elements with a one-component, ready-to-use, water and polyurethane-based adhesive.

To reproduce real situations and to support the walls, four steel structures were designed and built, capable to resist the shock impact of the explosions.

Table 1: Charge characteristics.

\begin{tabular}{|c|c|c|c|}
\hline \multirow{2}{*}{ Test \# } & Charge TNT & Scaled distance & Height charge \\
\cline { 2 - 4 } & $\mathrm{W}(\mathrm{kg})$ & $\mathrm{z}\left(\mathrm{m}^{1} \mathrm{~kg}^{1 / 3}\right)$ & $\mathrm{Hc}(\mathrm{m})$ \\
\hline T1 & 18 & 1.84 & 0.5 \\
\hline T2 & 25 & 1.71 & 0.7 \\
\hline T3 & 25 & 1.71 & 0.7 \\
\hline T4 & 38 & 1.49 & 0.7 \\
\hline
\end{tabular}

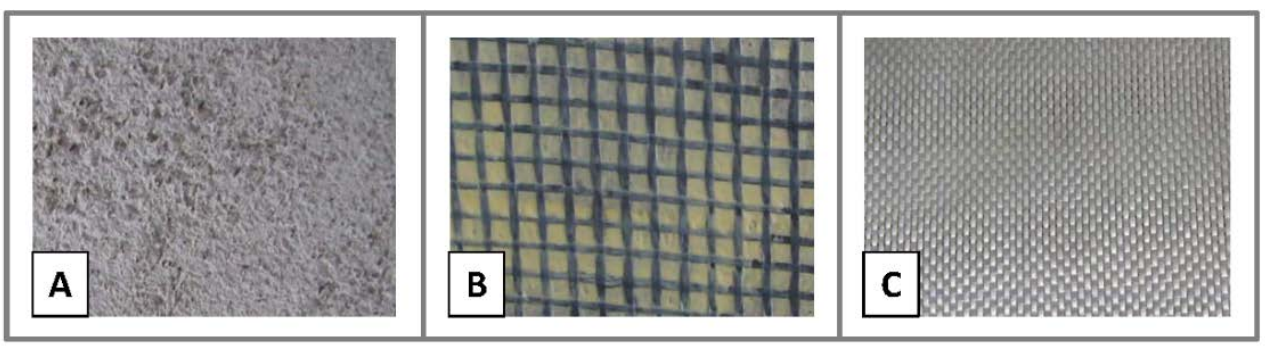

Figure 2: A: Fibre-reinforced mortar; B: Carbon-fibre mesh + adhesive; C: glass-fibre sheet + adhesive. 


\subsection{Instrumentation}

In order to characterize the explosion, the tests were monitored with pressures gauges, accelerometers, high-speed camera and conventional cameras. Fig. 1 shows the positions of the pressure gauges and accelerometers. Three pressure transducers (P1 to P3) were located on the floor at the same distance from the charge that the walls so the side-on pressure was recorded. Pressure gauges were high frequency with ablative protection and 5000 PSI range. One accelerometer was located on the back side of each wall (A1 to A4). Accelerometers were shock, ceramic-shear, with $5000 \mathrm{~g}$ range. Data acquisition system was a DATATRAP II, from MREL. It is a rugged and portable data acquisition system with 8 channels. The recording rate per channel was $10 \mathrm{MHz}$ with 14-bit resolution. The high-speed camera was a Photron FASTCAM (high-speed digital camera) SA3-120k. It is specially prepared to resist tests with explosives.

\section{RESULTS AND DISCUSSION}

The results of the first test, T1, were a very low damage even in the unreinforced wall so the charge was increased from 18 to $25 \mathrm{~kg}$ eq TNT for Test 2 and 3 obtaining an intermediate damage. Finally, in Test 4, with an explosive charge of $38 \mathrm{~kg}$ of TNT, the result was the complete collapse of the unreinforced wall and the wall with carbon fibre mesh (see Fig. 3).

\subsection{Sensors: pressure and accelerations}

Peak pressure registered on the different tests are listed in Table 2. Pressure gauges were located at the same distance from the charge that the walls so the side-on pressure measured also corresponds to the walls. Some of the pressure signals were lost probably due to impact over the pressure signal support. The maximum positive acceleration in $\mathrm{g}$ are reported in Table 3 for tests 1 to 3 . There is no acceleration data from T4 because no accelerometer was located due to the high risk of wall collapse. The peak acceleration ranges from $660 \mathrm{~g}$ to $1494 \mathrm{~g}$ in T3. Some of the acceleration signals were lost too, due to the cables and sensors were ripped and launched during the explosion. Accelerometers and pressure gauges were all triggered with the detonator so the time zero corresponds to the detonation initiation and the arrival time of the different signals can be used as a shock wave parameter. Fig. 4 shows an example of pressure and acceleration signal obtained in Test T1 from sensors P3 and A3.

The pressure histories registered support the fact that the explosive charge had a full detonation in all cases.

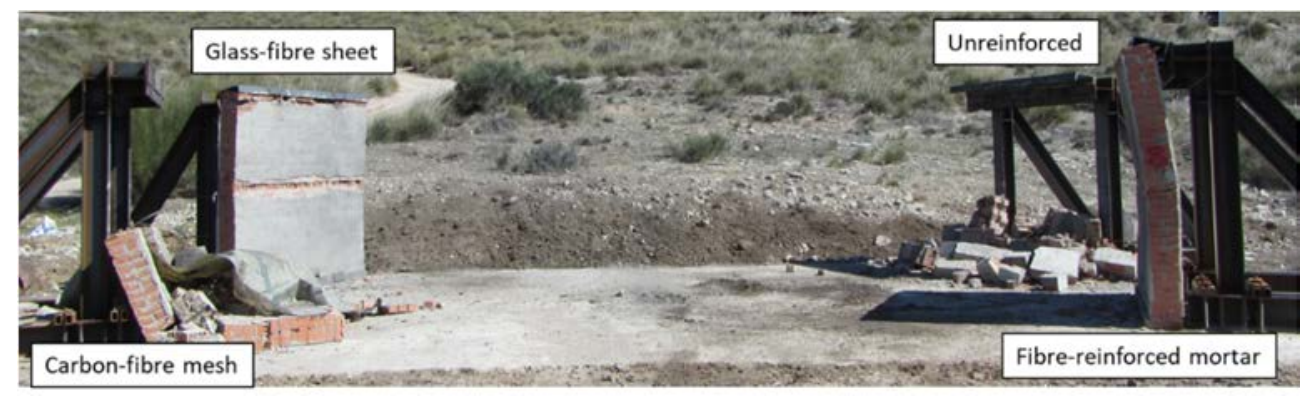

Figure 3: Results for Test number four (T4) 
Table 2: Side-on peak pressure in $\mathrm{kPa}$.

\begin{tabular}{|c|c|c|c|c|}
\hline & Test 1 & Test 2 & Test 3 & Test 4 \\
\hline Sensor & $\begin{array}{c}\text { Pso } \\
(\mathrm{kPa})\end{array}$ & $\begin{array}{c}\text { Pso } \\
(\mathrm{kPa})\end{array}$ & $\begin{array}{c}\text { Pso } \\
(\mathrm{kPa})\end{array}$ & $\begin{array}{c}\text { Pso } \\
(\mathrm{kPa})\end{array}$ \\
\hline $\mathrm{P} 1$ & 320 & 570 & 600 & 1251 \\
\hline $\mathrm{P} 2$ & 351 & $-^{\mathrm{a}}$ & 669 & - \\
\hline P3 & 443 & 552 & - & - \\
\hline
\end{tabular}

${ }^{a}$ No signal registered.

Table 3: Maximum positive acceleration in $\mathrm{g}$.

\begin{tabular}{|c|c|c|c|}
\hline \multirow{2}{*}{ Sensor } & Test 1 & Test 2 & Test 3 \\
\cline { 2 - 4 } & A $(\mathrm{g})$ & $\mathrm{A}(\mathrm{g})$ & $\mathrm{A}(\mathrm{g})$ \\
\hline $\mathrm{A} 1$ & $-^{\mathrm{a}}$ & - & 1243 \\
\hline $\mathrm{A} 2$ & 1043 & 1170 & 1330 \\
\hline A3 & 1210 & 660 & 1351 \\
\hline A4 & - & - & 1494 \\
\hline
\end{tabular}

${ }^{\text {a }}$ No signal registered.
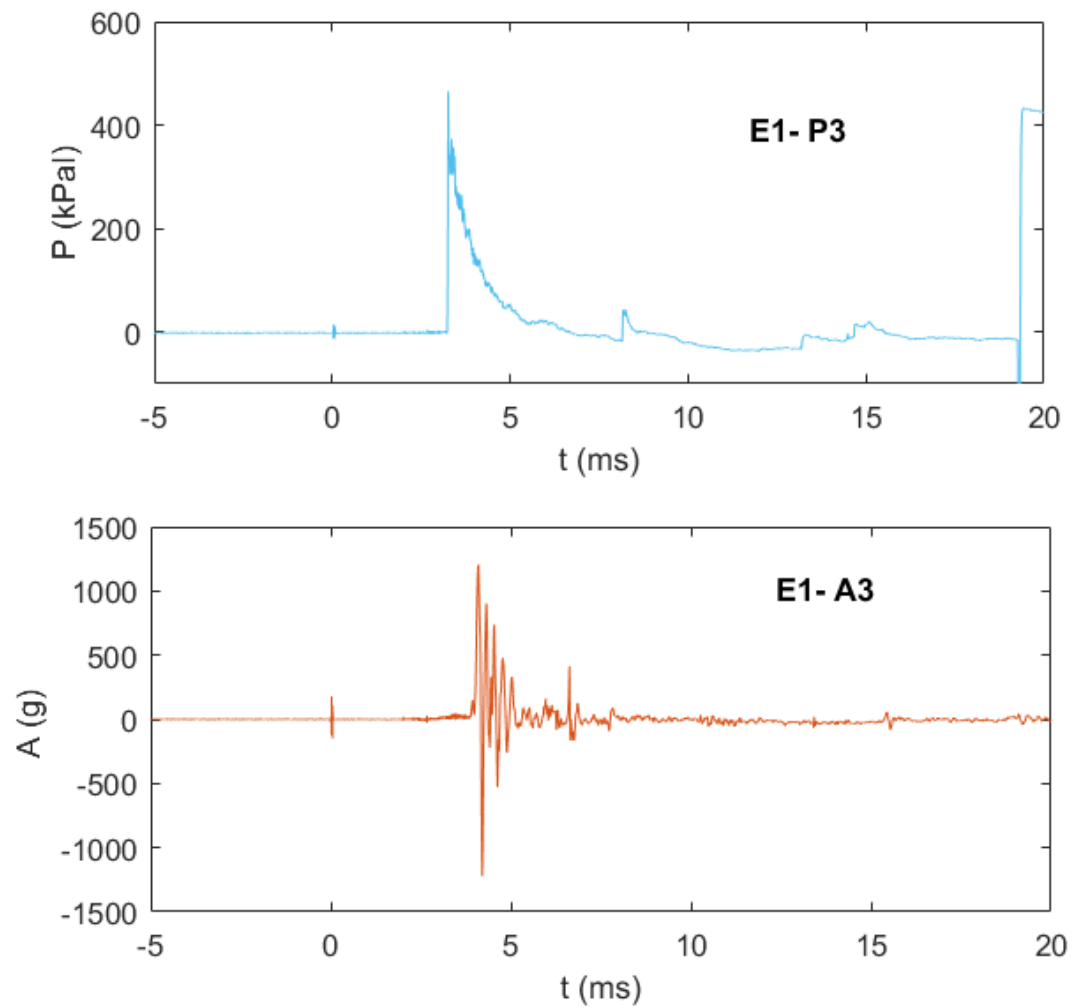

Figure 4: Example of pressure and acceleration signal. Test 1 pressure sensor P3 and accelerometer A3. 


\subsection{Damage evaluation}

Damage evaluation has been carried out in both faces of each wall in 20 points using a digital Schmidt hammer type L [7]. The methods based on the rebound principle consist on measuring the rebound of a spring-driven hammer after its impact with concrete. Although the rebound hammer [8] provides a quick, inexpensive means of checking the uniformity of concrete, it has some limitations that can affect the measurement like age of specimens, smoothness of test surface, moisture conditions of the concrete and type of cement and coarse aggregate.

ASTM Standard C805 "Standard Test Method for Rebound Number of Hardened Concrete" [9] was adopted as a standard test method in 1979. The 2002 version of the standard and the EU version EN 12504-2:2012 "Testing concrete in structures. Part 2: Nondestructive testing. Determination of rebound number" [10] state that this method is applicable to assess the in-place uniformity of concrete, to delineate regions in structure of poor quality or deteriorated concrete and to estimate in-place strength development. In this case, the objective is to find a variation in the rebound number after a blast event and not a direct strength correlation.

Damage was evaluated at 20 defined points in both faces of the sixteen walls. Each measurement point was defined by twelve points uniformly distributed around a rectangle: six for evaluation before and six for evaluation after the explosion. $Q_{1}$ is the median of the six points evaluated before the test $B_{i}$ and $Q_{2}$ is the median for the points after the test $A_{i}$. To ensure the reliability of the data, this template has been previously validated assuring that $B_{i}$ and $A_{i}$ come from the same population, so the differences between before and after the test could be detected.

The one tiled Wilcoxon rank-sum test [11] has been applied to each location point in order to assess if there is damage. This test is a nonparametric alternative to the two-sample t-test which is based solely on the order in which the observations from the two samples fall. The Wilcoxon test is still valid for data from any distribution whether Normal or not and is much less sensitive to outliers than the two-sample t-test. A p-value less than 0.05 shows that there has been decrease on the rebound number after the explosion with a $95 \%$ confidence level.

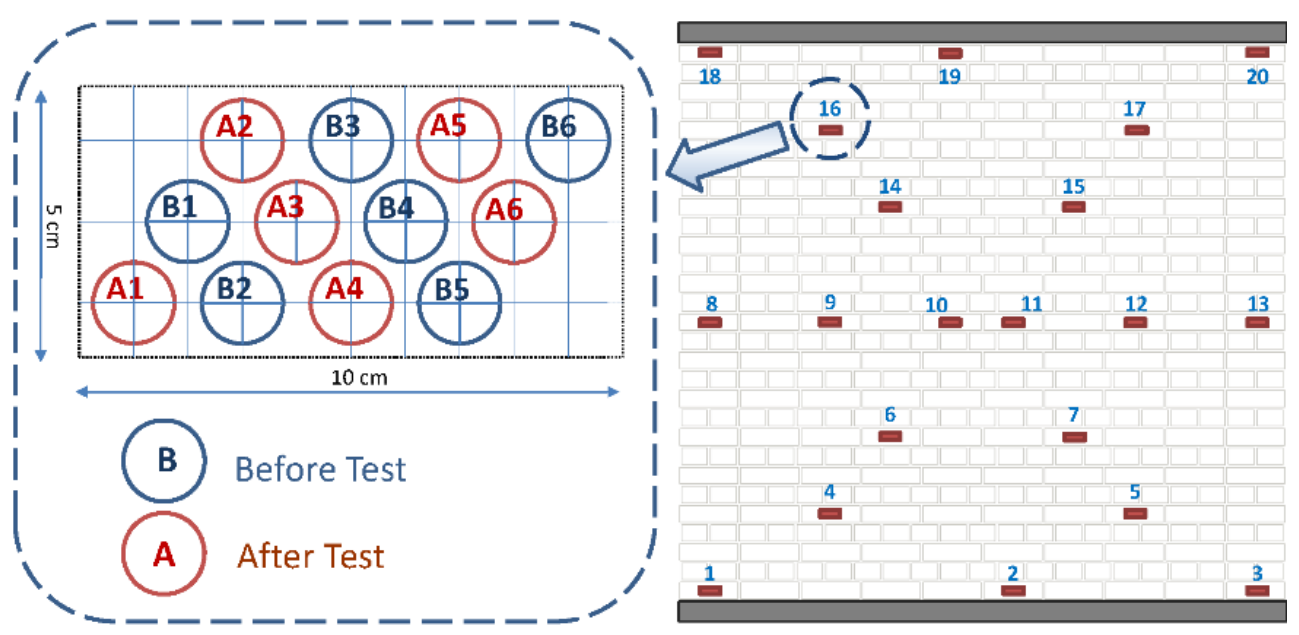

Figure 5: Evaluation template and location. 
We define damage $D$ as:

$$
\begin{aligned}
& p \leq 0.05 \rightarrow D=1-\frac{Q_{2}}{Q_{1}}, \\
& p>0.05 \rightarrow D=0,
\end{aligned}
$$

where $Q_{1}$ and $Q_{2}$ are now the mean of the six values before and after the test respectively. Damage value ranks from 0 for a "no-damage" point to 1 for a "total-damage". Damage 1 is assigned when the point is located in a surface where there is no possible rebound because of the incompetence of the material. Contour maps have been represented fitting a surface to the data with a triangle based cubic interpolation. Figs 6 and 7 show the contour maps for some tests. A grid of 200 linearly spaced points is created for each specimen at each direction (horizontal and vertical). The global considered damage, called $d_{200}$, can be defined as the mean of the interpolated values of these 200 points. Mean damage values obtained are listed in Table 4.

To complete the damage evaluation, the damage area $\left(d_{A}\right)$ has been used to rank the structures behaviour. It is defined as the ratio of the surface with total damage (damage equal to 1) and the total surface of the specimen, based on field data and not in damage maps. Additionally, the spalling fragments were collected and weighed.

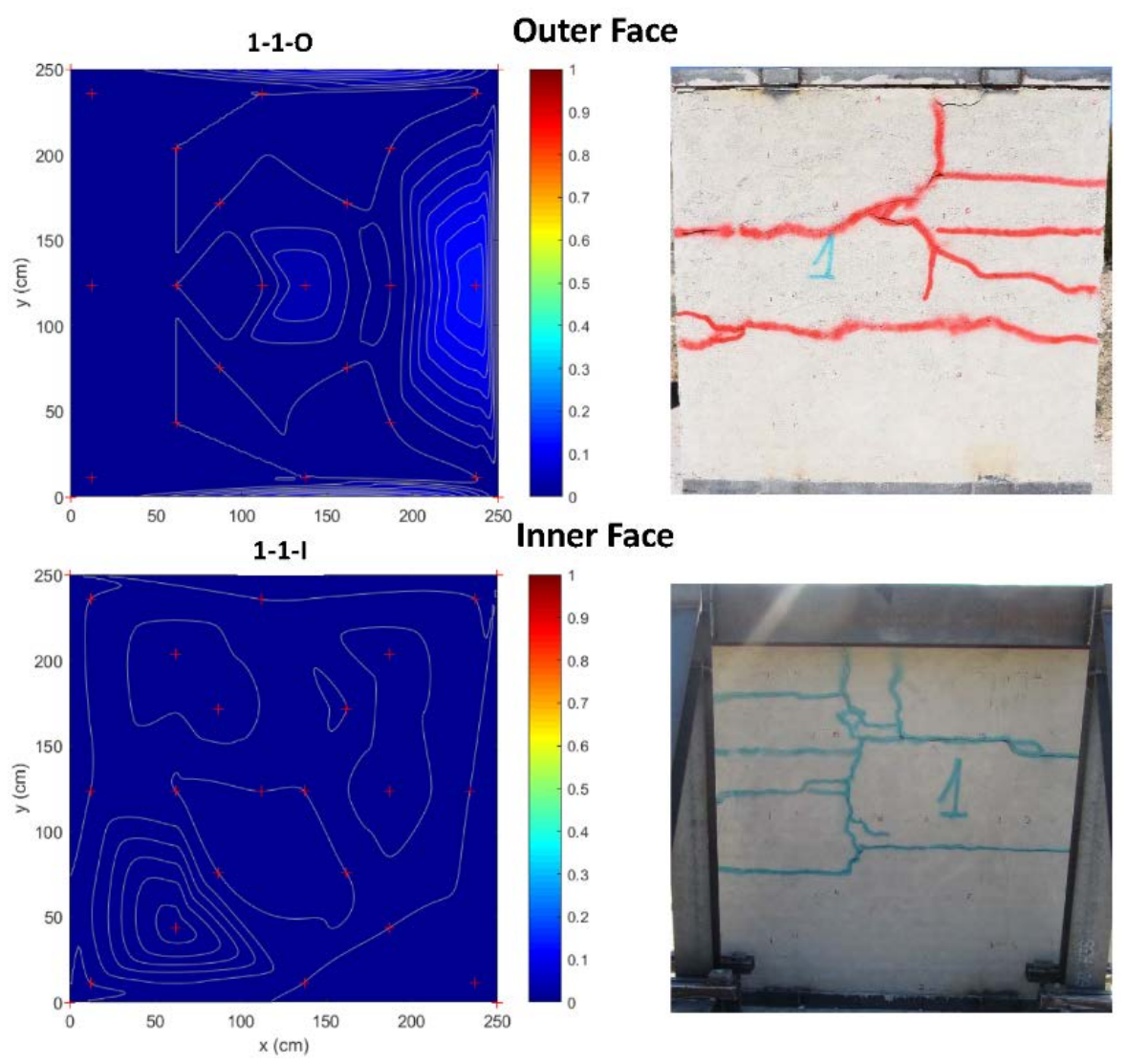

Figure 6: Damage maps for test one, wall one. 


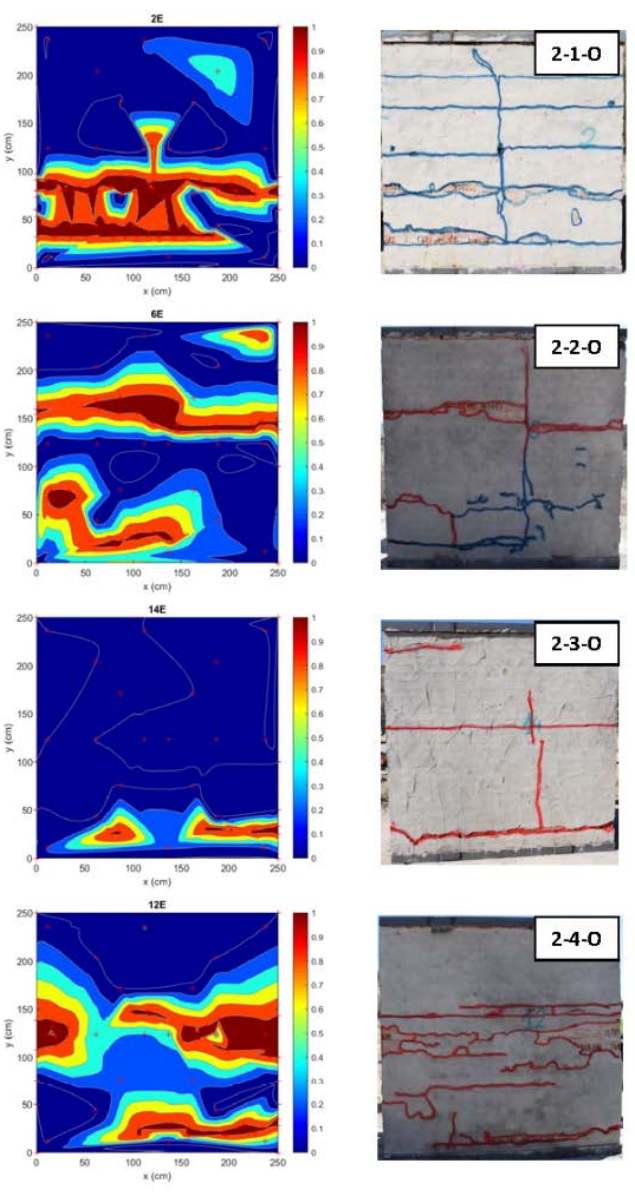

Figure 7: Damage maps for test two outer face.

In test number one, the damage value was minimum because of the low charge. Only little cracks were appreciated in both faces of the walls as shown in Fig. 6 for the non-reinforced wall.

Viewing the Table 4, it can be appreciated that although damage in outer face are higher in all the reinforced walls in test $\mathrm{T} 1$, in the inner face the damage is highly reduced.

For tests numbers two and three, charge was the same and higher that in number one, but the reinforcement was located for test number two in the outer face and in the inner one for number three.

Different lectures can be extracted from the results. In test number two (see Table 4 and Fig. 7), it can be observed that every solution improves the response of the wall but in different grades. In this case, the best candidate was the carbon-fibre mesh reducing the damage until $4 \%$ against $44 \%$ of the wall without reinforcement. Being the best solution, it must be seen that in the inner face was the most damaged. It could be due to the higher rigidity contributed by the mesh. In case of the glass-fibre sheet, it did not work correctly probably because the fabric was not well fixed with the glue to the wall as the temperatures were too low during the application. 
Table 4: Damage values obtained.

\begin{tabular}{|c|c|c|c|c|c|c|}
\hline \multirow{2}{*}{ Test } & \multirow{2}{*}{ Wall } & \multirow{2}{*}{ Face } & \multirow{2}{*}{ Reinforcement } & $d_{200}$ & $d_{A}$ & Fragment \\
\hline & & & & $\%$ & $\%$ & $\mathrm{~kg}$ \\
\hline 1 & 1 & Outer & Non-reinforced & 0.8 & & \\
\hline 1 & 2 & Outer & Fibre-reinforced mortar & 2 & & \\
\hline 1 & 3 & Outer & Carbon-fibre mesh & 9.29 & & \\
\hline 1 & 4 & Outer & Glass-fibre sheet & 4.39 & & \\
\hline 1 & 1 & Inner & Non-reinforced & 0.21 & & \\
\hline 1 & 2 & Inner & Non-reinforced & 0.08 & & \\
\hline 1 & 3 & Inner & Non-reinforced & 0.07 & & \\
\hline 1 & 4 & Inner & Non-reinforced & 0.11 & & \\
\hline 2 & 1 & Outer & Non-reinforced & 44.77 & 6.96 & 10.28 \\
\hline 2 & 2 & Outer & Non-reinforced & 38.24 & 3.65 & 5.15 \\
\hline 2 & 3 & Outer & Non-reinforced & 4.49 & 1.68 & 2.10 \\
\hline 2 & 4 & Outer & Non-reinforced & 20.33 & 5.71 & 7.75 \\
\hline 2 & 1 & Inner & Non-reinforced & 7.87 & & \\
\hline 2 & 2 & Inner & Fibre-reinforced mortar & 0 & & \\
\hline 2 & 3 & Inner & Carbon-fibre mesh & 10.88 & & \\
\hline 2 & 4 & Inner & Glass-fibre sheet & 5.5 & & \\
\hline 3 & 1 & Outer & Non-reinforced & 23.44 & 0.92 & 0.56 \\
\hline 3 & 2 & Outer & Fibre-reinforced mortar & 14.85 & & \\
\hline 3 & 3 & Outer & Carbon-fibre mesh & 17.11 & & \\
\hline 3 & 4 & Outer & Glass-fibre sheet & 7.25 & & \\
\hline 3 & 1 & Inner & Non-reinforced & 4.49 & & \\
\hline 3 & 2 & Inner & Non-reinforced & 1.19 & & \\
\hline 3 & 3 & Inner & Non-reinforced & 5.76 & & \\
\hline 3 & 4 & Inner & Non-reinforced & 0.61 & & \\
\hline 4 & 1 & Outer & Non-reinforced & - & - & \\
\hline 4 & 2 & Outer & Non-reinforced & 40.73 & 12.63 & 15.61 \\
\hline 4 & 3 & Outer & Non-reinforced & - & - & \\
\hline 4 & 4 & Outer & Non-reinforced & 31.73 & 14.06 & 20.76 \\
\hline 4 & 1 & Inner & Non-reinforced & - & - & \\
\hline 4 & 2 & Inner & Fibre-reinforced mortar & 3.68 & & 1.88 \\
\hline 4 & 3 & Inner & Carbon-fibre mesh & - & - & \\
\hline 4 & 4 & Inner & Glass-fibre sheet & 9.24 & & \\
\hline 4 & 2 & Outer & Non-reinforced & 40.73 & 12.63 & 15.61 \\
\hline
\end{tabular}


Special attention should be given to the fibre-reinforced mortar. Although apparently there was no superficial damage in the inner face, this is not a trusted result because actually was the most damaged with great cracks that break the wall completely. That was not reflected at the surface because of the material layer thickness $(15 \mathrm{~mm})$. As the rebound methodology only has into account the superficial layer, there is not a reliable method to evaluate the damage in this kind of material, even though it can be used combined with others.

In test number three, the results are different. Although it can be seen that the solutions improve the wall response, the behaviour of these have changed placing them at the outer face. Now the carbon-fibre mesh has a worse response, probably because the "fire ball" affects directly to the epoxy adhesive properties. Now the best candidate was the glass-fibre sheet, which worked correctly at this test. The fibre-reinforced mortar shows superficial damage in this case, since the material has received the shock impact but as well as in the previous test, the wall was broken and displaced.

For test number four, the charge was increased again. In this case, two walls collapsed: the unreinforced one and the wall with carbon-fibre mesh. In last case, two problems occurred: the mesh was not fixed correctly and the top support failed. The other two walls were seriously damaged, but glass-fibre sheet held the spalling mass perfectly.
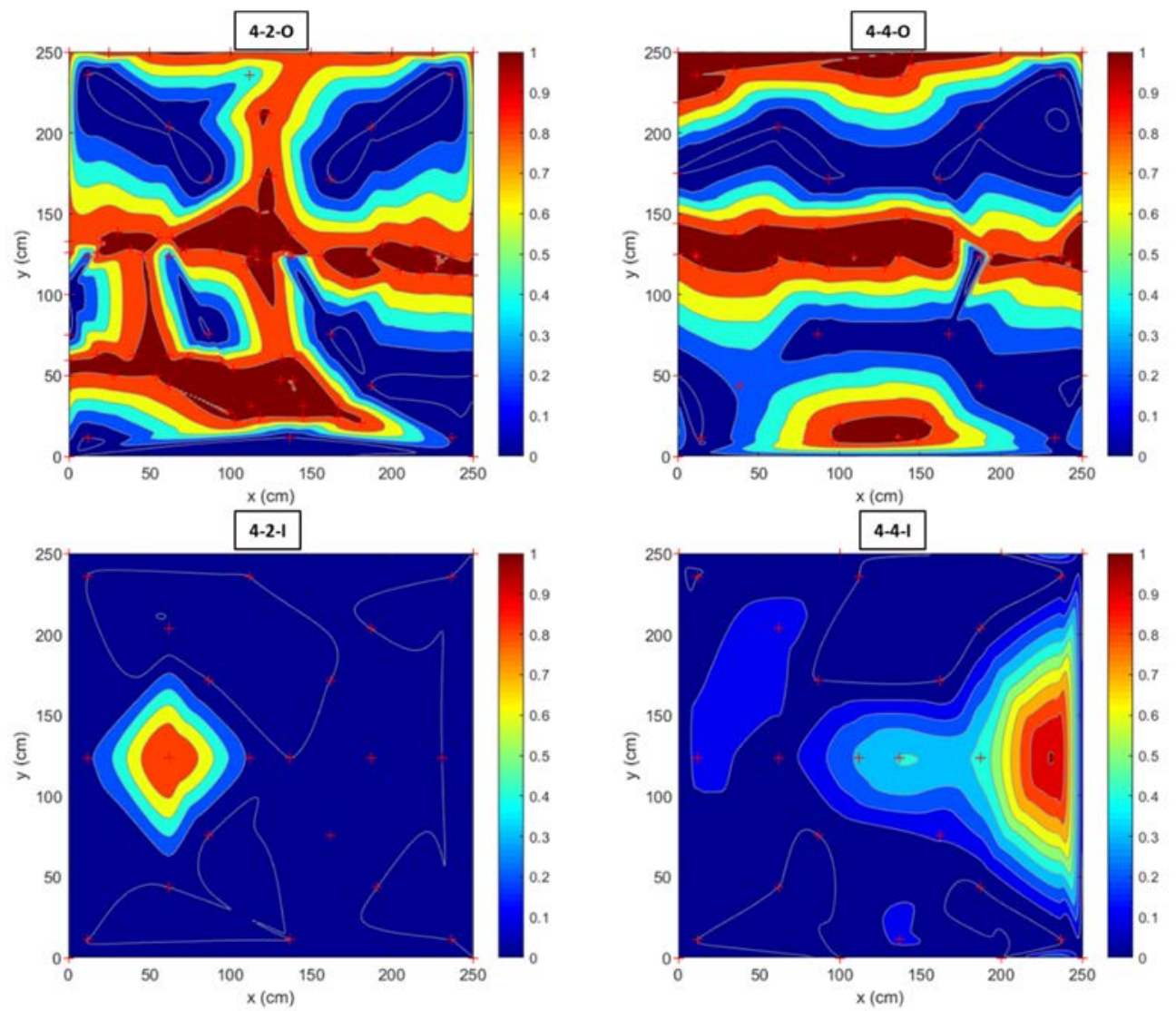

Figure 8: Damage maps for test four. Left figures correspond with the fibre-reinforced mortar wall and right figures with the glass-fibre sheet wall. 


\section{CONCLUSIONS}

Three different solutions have been tested to improve the strength of brick masonry walls against a blast event. All of them have shown to be well candidates for that purpose.

While the carbon-fibre mesh works better in the inner face, in the outer face its behaviour is slightly worse.

The glass-fibre sheet protects well in the outer face, avoid the collapse and hold the spalling mass perfectly when is correctly fixed.

Although the walls with fibre-reinforced mortar appeared with great cracks in test number two and three, the solution has shown a good behaviour against the collapse.

\section{ACKNOWLEDGEMENTS}

This research has been conducted under PICAEX project funded by the Centre for Industrial Technological Development (CDTI) Government of Spain. We would like to thank all the people from TAPUSA, MAPEI and FHECOR who contributed to the design and execution of the tests. We also thank the staff in La Marañosa (ITM - INTA) for their help at the testing site.

\section{REFERENCES}

[1] Davidson J.S., Fisher J.W., Hammons M.I., Porter J.R. \& Dinan R.J., Failure mechanisms of polymer-reinforced concrete masonry walls subjected to blast. Journal of Structural Engineering, 131(8), pp. 1194-205, 2005.

[2] Muszynski L.C. \& Purcell M.R., Use of composite reinforcement to strengthen concrete and air-entrained concrete masonry walls against air blast. Journal of Composites for Construction, 7(2), pp. 98-108, 2003.

[3] Buchan P.A. \& Chen J.F. Blast resistance of FRP composites and polymer strengthened concrete and masonry structures - A state-of-the-art review. Composites: Part B: Engineering, 38, pp. 509-522, 2007.

[4] Varma, R.K., Tomar, C.P.S., Parkash, S. \& Sethi, V.S., Damage to brick masonry panel walls under high explosive detonations. Structures Under Extreme Loading Conditions, ASME, PVP-Vol., 351, pp. 207-216, 1997.

[5] Ahmad, S., Elahi, A., Pervaiz, H., Rahman, A.G.A. \& Barbhuiya, S., Experimental study of masonry wall exposed to blast loadings. Materiales de construcción, 64(313), e 007, 2014.

[6] Chen, L., Fang, Q., Fan, J., Zhang, Y., Hao, H. \& Liu, J., Responses of masonry infill walls retrofitted with CFRP, steel wire mesh and laminated bars to blast loadings. Advances in Structural Engineering, 17(6), pp. 817-836, 2014.

[7] Corbett, D., Advancing the rebound hammer method: A new concrete test hammer. Non-destructive Testing of Materials and Structures, RILEM Book series, Springer, 6 , pp. 149-154, 2013.

[8] Malhotra, V.M., Surface hardness methods. Handbook on Non-Destructive Testing of Concrete, 2nd ed., eds V.M. Malhotra \& N.J. Carino, CRC Press, 2004.

[9] ASTM, American Society for Testing and Materials. ASTM C805-02 - Standard Test Method for Rebound Number of Hardened Concrete, 2002.

[10] EN 12504-2:2012, Testing concrete in structures. Part 2: Non-destructive testing. Determination of rebound number, 2012.

[11] Bergmann, R., Ludbrook, J. \& Spooren, W.P.J.M., Different outcomes of the Wilcoxon-Mann-Whitney test from different statistics packages. The American Statistician, 54(1), pp. 72-77, 2000. 